\title{
Konseling Eklektik Dengan Kerangka Kerja Skilled Helper Model
}

\author{
Yulianti D wi Astuti \\ Prodi Psikologi Fakultas Psikologi dan Ilmu Sosial Budaya \\ Universitas Is lam Indonesia \\ yulianti.dwiastuti@ui i.ac.id
}

\begin{abstract}
Abstrak
Pendekatan eklektik atau integratif saat i ni muncul sebagai salah satu altern atif andalan dalam pemberian intervensi psi kologi dibandingkan penggunaan pendekatan konseling mur ni. Artikel ini mencoba untuk memberikan gambaran tentang pelaks anaan konseling eklektik yang mengkombinasikan pendekatan Person Centered dan Rational Emotive Behavior dengan kerangka kerja Skilled Helper Mo del dari Egan. Person Centered dipilih karena klien merasa tidak dit erima oleh lingkungan sehingga ti dak dapat beraktualisasi diri dengan baik. Adapun Rational Emotive Behavior diper lukan karena sumber masalah klien adalah pada kecenderungannya untuk berfikir tidak rasional dan melemahkan diri. Oleh kar ena itu, setelah klien meras a diterima sepenuhnya oleh ko ns elor, klien kemudian diajari untuk mengubah fikiran dan keyakinannya dengan merekonstruksi persepsi dan fikirannya agar menjadi lebih logis dengan menggunakan teknik dan tata cara yang s esuai. Untuk memastikan proses k onseling berjalan dengan teratur dan memberikan hasil, konselor m enjadikan model Skilled Helper dari Egan s ebagai kerangka kerja dalam melakukan sesi konseling ini.
\end{abstract}

Kata kunci: Person Centered, Rational Emotive Behavior, Skilled Helper Model

\section{Pendahuluan}

Bidang ilmu psikologi memiliki banyak pendekatan dalam teori maupun aplikasinya. Meskipun semua pendekatan ini memiliki beberapatujuan yang sama, tetapi masing-masing memiliki rute yang berb eda untuk mencapai tujuannya. Beberapa intervensi membutuhkan sikap aktif dan direktif pemberi intervensi, sementarayanglain mengedepankan klien sebagai agen aktif.Beberapa terapi fokus pada mengalami emosi, sementara yang lain menekankan identifikasi pob kognitif, atau berkonsentrasi pada perilaku y ang ditunjukkan klien. Dengan semua keragaman ini, tentu sulit bagi seorang praktisi untuk dapat mengembangkan keterampilannya dalam semua teknik yang ada.

$$
\text { Bidang konseling di awal }
$$
kemunculannya dipenuhi dengan perang teori. Mencari kes amaan di antara berbagai si stem intervensi adalah hal yang relatif baru. Selama beberapa dekade, para ahli menolak in tegrasi. Norcross \& Beutler (Corey, 2015) menyatakan bahwa baru sejak awal 1980-an, integrasi berkembang menjadi lebih jelas dan saat ini telah menjadi gerakan yang mapan dan dihormati serta diandalkan. Mulai s aat itu para peneliti dan praktisi psikologi tidak lagi mencari pendekatan k on seling murni mana yang paling efektif, tetapi mulai mengalihkan fokus risetnya pada identifikasi faktor-faktor umum atau non spesifik yang secara universal efektif dalam semua pendekatan utama 
konseling. Perubahan ini menyebabkan run tuhnya batas an-batasan y ang kaku antar paradigma dan memengaruhi perkembangan dan peningkatan popularitas pendekatan integratif dan eklektik.

Menurut Kamus Psiko logi APA (https:// dictionary.apa.org/), konseling eklektik adalah teori atau praktik konseling yang menggabungkan doktrin, temuan, dan teknik yang dipilih dari beragam sistem teoretis. Pendekatan eklektik juga dikenal sebagai konseling integratif. Ori entasi pendekatan eklektik adalah penggabungan te or i-teor $\mathrm{i}$ konseling dengan mempertimbangkan kelebihan dan kekurangan pada masingmasing teori tersebut. Karena dalam praktiknya pendekatan eklektik menggunakan semua teori kon seling, maka pendekatan ini ti dak pern ah menggunakan konsep-k ons ep teori secara tetap, tetapi akan memilih konsep teori apakah yang paling sesuai dengan masalah peserta didik. Oleh karena itu, pendekatan eklektik bersifat fleksibel dalam penggunaannya. Selain itu, pendekatan eklektik juga ber sifat ilmiah, sistematik, dan logis.

Menurut Lapworth et.al (Faris \& van Ooijen, 2012),integrasi merupakan istilah yang berguna untuk mengakomodasi berbagai pendekatan yang melampaui bentuk murni dengan memasukkan pluralisme, transtheoreticism, faktor umum, eklektisme, relasional dan pendekatan dekonstruksionis.

Konselor yang berpegang pada pola eklektik berpen dapat bahwa mengikuti satu orientasi teoritis serta menerapkan satu pendekatan saja akan membatasi ruang gerak ko ns elor. Sebaliknya dengan menggunakan variasi dalam sudut pandang, prosedur dan teknik, konselor dapat memberi layanan konseling yang lebih sesuai dengan kebutuhan serta ciri khas masalah yang dihadapi masingmasing klien. Ini tidak berarti bahwa konselor berpikir dan bertindak seperti orang yang bersikap opportunis, dalam arti diter apkan saja pandangan, pros edur dan teknik yang kebetulan membawa hasil yang paling baik tanpa berpegang pada prinsip-prinsip tertentu. Kon selo r yang berpegang pada pola eklektik harus menguasai sejumlah prosedur dan teknik s erta memilih dari prosedur-prosedur dan teknik-teknik y ang ters edia, mana y ang dianggapnya paling sesuai dalam melayani klien tertentu (Winkel \& Hastuti, 2010).

Pendekatan faktor non-spesifik atau umum untuk integrasi ini berupaya mengungkap dan memanfaatkan sebaik mungkin hal-hal yang dianggap se bagai unsur inti yang universal dari efektif di semua pendekatan konseling utama. Duncan et.al (Kaslow \& Lebow, 2 002) menyatakan, yang terpenting paradigma ini berusaha untuk lebih menekankan pada unsur-unsur apa yang dianggap klien efektif dibandingkan apa yang dipikirkan oleh pemberi intervensi dan peneliti.

Grencavage dan Norcross (Wo sket, 2007) mengidentifikasi faktor-fakt or umum dalam beragam pendekatan konseling yang 
terdapat pada 50 publikasi ilmiah dan mengk ategorikannya menjadi lima kelompok utama sebagai berikut:

1. Karakteristik klien seperti harapan positif, keaktifan klien mencari bantuan.

2. Kualitas pemberi intervensi seperti kehangatan, empati, penerimaan.

3. Proses perubahan, misalnya kesempatan untuk katarsis, penguasaan dan penerapan perilaku baru, pengembangan waw asan/kesadar an, pengalaman sukses dan keberhasilan, pembelajaran emosi dan interper sonal.

4. Struktur tritmen contohnya penggunaan teknik, pengaturan tritmen, setting yang mendukung penyembuhan, fokus pada inner world (batin) dan eks plorasi dari masalah emosi.

5. Elemen hubungan, misalnya pengembangan hubungan terapeutik, keterikatan dan transferensi.

Dari daftar di atas dapat disimpulkan bahwa terdapat faktor kompleks yang bekerja dalam setiap pendekatan yang efektif dan bahwa teknik dan strategi hanya membentuk sebagian kecil dari keseluruhan per ubahan.

\section{Pe rtu mbu han pe ndekatan eklektik dan integratif}

Pengakuan yang berkembang bahwa faktor-fakt or umum muncul dalam semua pendekatan konseling utama sebagai agen perubahan universal telah memberikan kon tribu si signifikan te rhadap gerakan y ang dapat diamati menuju eklektisisme dan integrasi dalamdunia konseling.Sebuah survey yang dilakukan kepada para professional helper di Amerika Utara men emukan bahwa $50-75 \%$ praktisi lebih menyukai beberapa jenis intervensi eklektik (Lambert, 2013).

Gerakan integratif/eklektik, banyak mengambil bentuk awalnya dari paradigma faktor-fakt or umum, kemudian dibentuk oleh akumulasi bukti penelitian yang semakin meningkat. Beberapatemuan kunci dirangkum Wosket (2016) s ebagai berikut:

a. bahwa konseling dan psikoterapi umumnya efektif, tidak ada yang lebih menonjol dari yang lain. Ini berarti mustahil untuk memastikan pendekatan (atau pendekatan) mana yang lebih efektif daripada yang lain. Dengan ditemukanny a 'fenomena hasil yang sama' - ini maka disimpulkan bahwa pendekatan yang berbeda dapat mencapai hasil yang sama

b. bahwa kesetaraan hasil tersebut sebagian b esar ditentukan oleh fak torfaktor umum di seluruh pendekatan.

c. bahwa pemberi intervensi dan klien yang cocok dengan berbagai variabel adalah prediktor penting hasil 'paradoks kes etaraan', yang menunjukk an bahwa pemberi intervensi berpengalaman (terlepas dari orientasi) lebihmirip dalam cara prakteknya dan bahwa semakin berpengalaman praktisi, semakin besar kemungkin an dia akan beker ja secara integratif. Pengalaman (bukannya teori) 
mendor ong pemberi intervensi yang lebih berpengalaman untuk menggunakan beragam pendekatan.

d. bahwa asisten paraprofesiona menggunakan berbagai keterampilan yang sama efektifnya dengan pemberi intervensi yang terlatih secara profesional dalam beberapa konteks bahwa agen perubahan utama dari kons eling atau psikoterapi yang efektif adalah kepribadian pemberi interv ensi, bukan teori atau model yang digunakan - terutama kemampuan untuk membentuk hub ungan yang hangat dan suportif

e. bahwa sejumlah penelitian mungkin menghasilkan perubahan terapeutik yang dikaitkan dengan pendekatan tertentu apadah perubahan itu sebenarnya dipengaruhi oleh pemberi intervensi.

\section{Skilled HelperModel sebagaikerangka kerja yang terintegrasi}

Hollanders (Woolfe, Strawbridge \& Douglas, 2009) menyatakan bahwa Skilled
Helper Model meru pakan salah satu ker angka kerja eklektisisme sistematis atau teknis. Ini didasarkan pada argumen bahwa model tersebut memungkinkan konselor untuk secara sistematis menggunakan berbagai keter ampilan dan s trategi y ang dis esuaikan dengan berbagai tahap proses konseling. Jenkins (2000) lebih suka m elihatnya s ebagai model integratif karena Skilled Helper Model memberikankerangka kerjamenyeluruh untuk proses bantuan namun tidak mengacu pada salah satu teori tertentu.

Jenkins (2000) berpendapat bahwa Skilled Helper Model secara dominan mengacu pada nilai-nilai dan prinsip person centered dan pendekatan cogn itive-behavior. Adapun Coles (Wosket, 2008) menyatakan kapasitas mo del ini untuk mengintegrasikan gagasan psiko dinamik dengan pers pektif cognitivebehavior dan humanistik. Egan sendiri menggambarkan model ini sebagai kerangka kerja integrasi yang akan membantu konselor mengembangkan landasan y ang kuat untuk membentuk orientasi kons elingnya sendiri (Egan, 2014). 


\section{The Problen-Managemeat Framew urk}

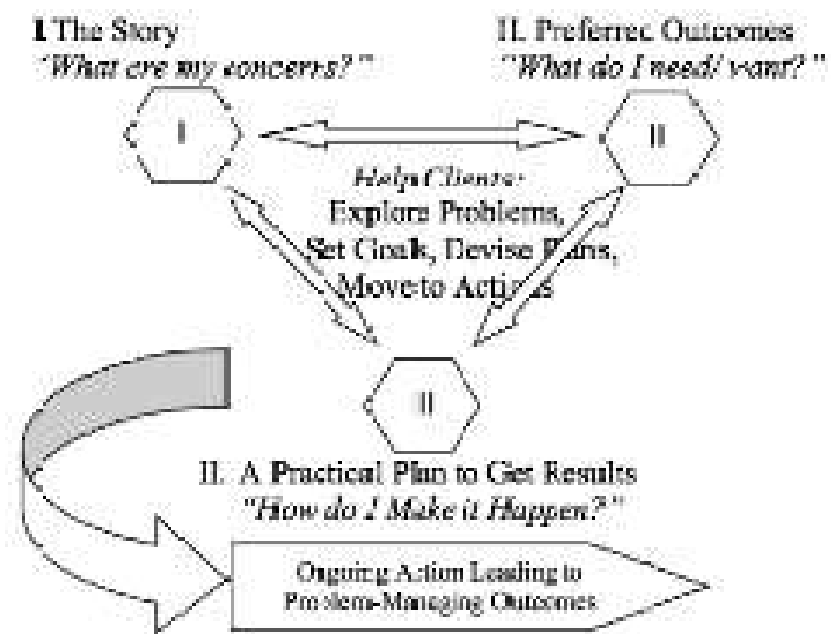

Gambar 1. Kerangka Kerja Pengelolaan Masalah 3 Tahap (Egan, 2014)

Model ini dapat me mbantu klien untuk memahami per mas alahan- per mas alahann ya dengan lebih jelas, menentukan apa yang dii nginkan klien dan mera ncang mas a depan yang lebih baik dan membentuk serta memilih strategi-strat egi tindakan yang sesuai. Secara umum, model Skilled Helper dari Egan (2014) ini memiliki tiga tahapan yaitu: Skenario sekarang, skenario yang diinginkan dan strategi tindakan.

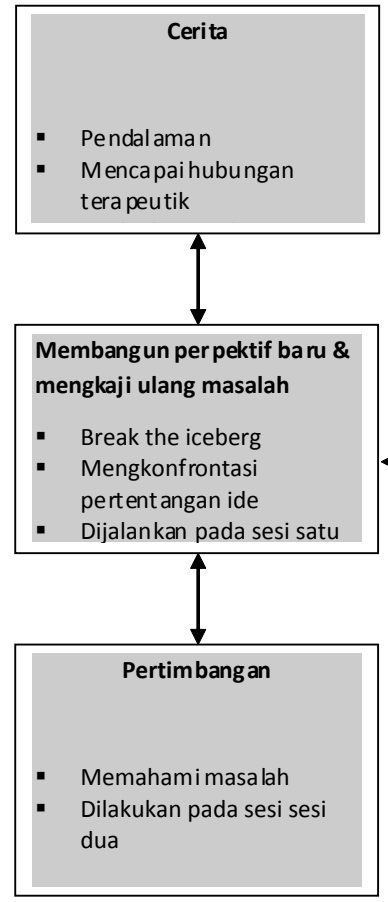

Kondisi Sekarang
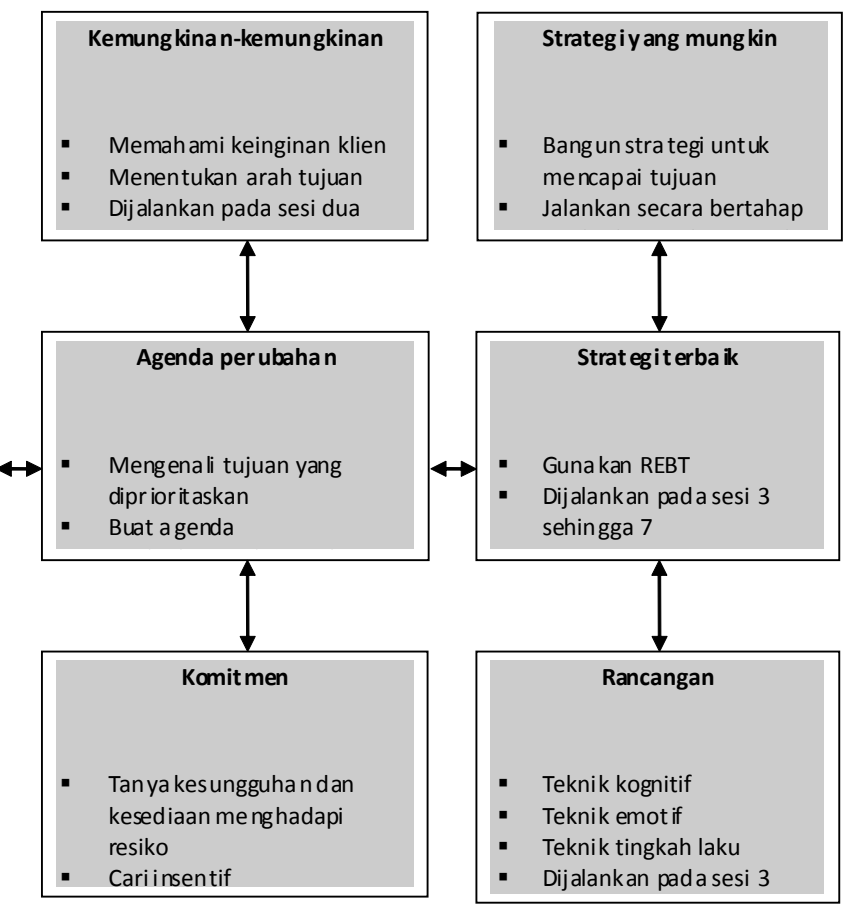

Kondisi yang Diharapkan Tindakan Bagan 1. Model Egan 


\section{Penerapan Kon seling Eklektik dengan Kerangka Kerja Model Egan}

Berikut ini akan dijabarkan contoh pelaksanaan konseling eklektik pada salah satu kasus. Dalam konseling ini, klien akan mendapat intervensi dengan menggunakan pendekatan client centered di bagian awal konseling dan dilanjutkan dengan penerapan konseling rational emotive behavior pada saat kon selor telah mengetahui bahwa sumber masabh klien ada pada keyaki nan-keyakinan ir asionalnya. Penerapan konseling dilakukan dengan kerangka kerja Skilled Helper Model dari Egan.

\section{SkenarioSekarang}

Tahap ini dijalankan pada sesi konseling yang pertama dan kedua. Pada tahap pertama ini, konselor melakuk an tiga tugas, yaitu:

1. Menjalin hubungan terapeutik atau psikologis untuk mendorong klien bercerita dan mengungkapkan is $\mathrm{i}$ hatinya, khususnya mengenai permasalahan yang dialami kepada konselor.

Hubungan terapeutik yang baik akan membuat klien menerima konselor dengan hati yang terbuka dan mempercayai konselor. Konselor memulai sesi dengan membuat penstrukturan. Konselor menjelaskan kepada klien apakah pengertian dan tujuan konseling, bagaimana proses konseling akan berjalan serta etika yang ada.

Konselor kemudian meminta klien untuk menceritakan masalah yang sedang dihadapi klien sehingga dia datang untuk meminta layanan konseling. Ketika klien menjelaskan permasalahannya, konselor menc oba memahami dengan baik dan betul cerita tersebut Berdasarkan masalah-masalah yang dikemukakan oleh klien, konselor mengidentifikasi tema cerita dan permasalahan yang sebenarnya. Selanjutnya konselor membantu ki en untuk menyadari blind spot yang menghalangi mereka untuk melihat masalah yang sebenarnya. Klien dibantu membuat perspektif baru dan mengkaji ulang masalah mereka. Klien disadarkan bahwa ada sesuatu masalah y ang perlu diselesaikan dan dia sendiri perlu berperan aktif dalam proses penyelesaian tersebut.

\section{Contoh:}

Kl ien datang dengan mengeluhkan masalah penyesuaian dirinya dengan sesama penghuni asrama. Menurut klien hal itu terjadi karena teman-temannya menolak keberadaan dirinya yang dicurigai sebagai lesbian karena perilakuny a yang "berbeda" dengan temanteman lainnya. Konselor kemudian menany akan kepada klien apakah kecur igaan teman- temannya itu benar? Klien mengakui bahwa dia memang pernah menjadi lesbian sewaktu bekerja beberapa tahun di luar negeri, tetapi saat ini dia dalam proses untuk berhenti. Mes kipun begitu, karena tinggal satu asr ama dengan banyak perempuan, kli en terk adang masih memiliki rasa suka yang intens kepada teman seasramanya dan dia mengalami kesulitan untuk membedakan apakah yang dia rasakan itu adalah perasaan suka sebagai 
teman, adik, atau rasa cinta. Perasaannya tersebut mempengaruhi perilaku kesehariannya terhadap perempuanperempuan yang dia sukai sehingga menimbulkan rasa risih dari yang bersangkutan maupun t eman-teman yang lain.

2. Konselor menangkap beberapa inti permasalahan dan meminta klien untuk membuat penjelasan lebih mendalam (break the iceberg).

\section{Contoh:}

Klien mengatakan bahwa dia pernah menjalani kehidupan sebagai lesbian'! Konselor meminta klien untuk menjelaskan lebih mendalam kapan hal itu terjadi dan apakah yang meny ebabkan hal itu terjadi?

Berdasarkan berbagai penjelasan klien, konselor dapat mengetahui dengan jelas bahwa klien menjadi lesbian lebih karena faktor lingku ngan karena dalam keluarganya tidak ditemukan riw ayat homoseksualitas ini. Sejak kecil sampai remaja kli en sama sekali ti dak memil iki ketertarikan kepada s esama perempuan. Sewaktu SMA klien juga pernah berpacaran dengan beberapa lelaki. Beberapa fator yang ditengarai menjadi penyebab klien berubah menjadi lesbian adalah:

a. Klienmengalami traumakarena mengalami berbagai pengalaman buruk dengan lelaki:

1) Ayah kandung meninggalkan ibunya dan tidak peduli terh adap klien. Oleh karena itu klien memiliki kebencian yang amat dalam kepada ayahnya.
2) Klien pernah dijual sebagai pelacur oleh bibinya dan dipaksa melakukan hubungan seksual dengan banyak lelaki

3) Klien pernah diperkosa oleh mertua atasannya di luar negeri

b. Rumah tangga orang tua klien yang tidak pernah damai dan kemudian berakhir dengan perceraian dan perebutan anak menyebabkan klien mer asa hatinya terbelah dua.

Klien tidak mau terlalu dekat dengan ibu karena takut menyaki ti ayah, sebaliknya klien juga tidak mau dekat dengan ayah karena takut dianggap mengkhianati ibunya. A kibatnya kl ien kekur angan perhatian dan kasih sayang dari kedua orang tuanya.

c. Klien selalu menilai dirinya sebagai or ang yang tidak baik dan telah rus ak karena dia pernah dijual sebagai pelacur, menjalani kehidupan sebagai lesbian, dan diperkosa oleh mertua atasan.

Keadaan ini menyebabkan klien memiliki perasaan rendah dir i, terutama bila berhubungan dengan lelaki. Akibatnya, jika kl ien mulai menyukai lelaki, dia cenderung menghalanginya dengan memunculkan sikap yang bertentangan (memben ci lelaki) sebagai mekanisme pembelaan $d$ iri.

d. Klien awalnya tertarik menjadi lesbian karena merasa mendapatkan kasih sayang dan perhatian teman kerjanya 
Klien yang selama i ni tidak memperoleh kasih sayang dari keluarganya merasa disirami air sejuk saat mendapat perhatian dan diistimewakan oleh temannya tadi. Segala permintaan klien juga dikabulkan s ehingga kl ien mer asa memiliki keterikatan fisik dan emosi yang mendalam sampai akhirnya memiliki pengalaman seks ual dengan sesama jenis.

Ko nselor juga melakukan k on frontasi ketika menemui adanya pertentangan pandangan dalam diri klien

\section{Contoh:}

a. Klien mengatakan bahwa dirinya adalah orang yang tidak baik, sementara klien juga mengatakan bahwa dia selalu berus aha memaafkan perbuatan jahat orang lain terhadapnya, selalu perhatian terhadap orang lain, rajin menjalankan ibadah, dan lain- lain

b. Klien mengatakan bahwa dia tidak peduli dengan perkataan dan anggapan orang lain terhadap diriny a tetapi ko ns elor menunjukk an bahwa sebetulnya klien mudah terpengaruh oleh pandangan ataupun pendapat orang lain karena jika ada orang yang memiliki pendapat negatif tentang dirinya maka klien akan menjadi ragu, marah, kecewa dan ti dak bersemangat melakukan aktivitas apapun.

c. Klien mengatakan bahwa dia bertekad untuk tidak menjadi lesbian lagi, tetapi dia mengatakan mas ih menyukai wanita

'! kons elor menanyakan apakah klien memang bersungguh-sungguh ingin berubah ataukah sekedar memenuhi tuntu tan lingk ungan

3. Pada tahap ini juga, kon selor dan klien bersama-sama men coba memahami masalah yang dihadapi oleh klien dan perlu diselesaikan.

Kare na masalah yang dikemukakan klien ada beberapa, maka konselor membantu klien memilih masalah-masalah penting yang akan diprioritaskan.

Dalam tahap ini telah dikenali beberapa masalah penting, yaitu:

a. Klien ingin berhenti menjadi lesbian, tetapi masih merasa ragu apakah dia dapat melakukannya. Norma-norma agama dan so sial yang dipercayai klien menyatakan bahwa menjadi lesbian adalah perbuatan yang salah dan berdosa sehingga klien merasa tertekan. Stres ini menjadi bertambah berat karena lingkungan juga men entang perbuatan ters ebut dengan menunjukkan sikap tidak bersahabat serta selalu memberi teguran kepada klien. Klien telah berusaha untuk tidak lagi menjadi lesbian (dengan cara menghindari perempuan yang dia s ukai), tetapi usaha ters ebut belum memb erikan hasil. Klien mengatakan bahwa dia masih memiliki dorongan untuk menyukai sesama wanita. Bahkan adakalanya klien takut 
menjalin hubungan persahabatan dengan sesama wanita karena khawatir perasaan sukanya tersebut akan berganti menjadi rasa cinta.

b. Klien mengalami gangguan penyesuaian diri dengan teman seasramany a. Hal ini disebabkan temanteman asramany a mengetahui bahwa kl ien a dalah seor ang lesbian sehingga memb erikan berbagai label yang negatif kepada klien. Permasalahan di asrama ini dapat dibedakan menjadi atas dua: (1) Klien mendapat tentangan dari orang-orang yang memang menganggap lesbian sebagai abormalitas, (2) Klien mendapat tentangan dari orang-orang yang sebenarnya juga lesbian tetapi tidak mau mengungkapkan identitas mer eka yang sebenarnya (coming out) dan menganggap klien sebagai saingan ataupun pember ontak. Kli en seolah-olah tidak memerlukan or ang lain ("saya tidak peduli dengan perkataan dan anggapan or ang lain terhadap saya") tetapi sebenarnya klien mudah terp engar uh oleh pandangan a taupun pendapat orang lain ("saya ingin membuktikan bahwa saya tidak seburuk yang mere ka kir a").

c. Terdapat berbagai keyakinan tidak rasi onal dalam diri kli en seperti: "Saya adalah seora ng yang tidak b aik/ rus ak", "Semua lelaki adalah jahat".

\section{Skenarioyang Diinginkan}

Pada tahap kedua ini, konselor membantu klien untuk:

1. Mencari kemungkinan-kemungkinan yang lebih baik di masa depan

Pada tahap ini, kons elor membantu klien untuk menetapkan arah tujuan dan mencoba membebas kan klien dari permasalahan y ang sedang dihadapiny a. Hal ini dimulai dengan membantu klien mengetahui apa yang di inginkannya dan apa saja y ang diperlukan untuk berubah.

Hal-hal yang di inginkan klien yaitu: (1) Klien ingin berhenti menjadi lesbian dan dapat mengontrol perasaan tertarik ny a terh adap sesama wanita (3) Klien ingin dapat menyesuaikan diri dengan orang lain (4) Klien ingin mengurangi tingkah lakunya yang dapat menimbulkan penilaian negatif orang lain terhadap dir inya (5)Klien ingin dapat menjalin pers ahabatan dengan sesama wanita tetapi tidak membuatnya terjerumus menjadi lesbian lagi (6) Klien ingin dapat menyu kai lelaki lagi (7) Klien ingin dapat mengatasi kecemasannya setiap mendengar penilaian negatif or ang terhadap dirinya (8) $\mathrm{Klien}$ ingin menghilangkan perasaan rendah dirinya (9) Klien ingin menunjukkan kepada or ang lain bahwa dirin ya juga memiliki kelebihan dan (10) Klien ingin memperbaiki hubungannya dengan keluarganya

Sumber kekuatan y ang dimiliki klien: Klien adalah seorang yang memiliki kemampuan kognitifyang baik, Klien memiliki 
berb agai minat, $\mathrm{Kl}$ ien dapat menc urahkan isi hatinya dengan lancar (verbal fluency), Klien memiliki rasa ingin tahu yang cukup besar, Klien merupakan or ang yang tabah dan tidak mudah menyerah dan Klien memil iki sifat mandiri (independence) .

2. Bergerak dari kemungkinan kepada pilihan.

Konselor dan klien bersama-sama mengenali tindakan-tindakan yang perlu diambil oleh klien untuk menangani masalah yang dihadapinya dan apakah pilihan yang ter baik bagi klien. Agen da y ang dibuat klien harus bersifat realistik, menantang dan memb erikan hasil, s esuai dengan nilai-nilai klien, dan waktunya mencukupi.

Dengan mempertimbangkan skope tujuan, tingkat kesulitan dan sumber kekuatan yang ada pada diri kli en, maka klien memilih untuk fokus terlebih dulu kepada masalah gangguan penyesuaian dirinya dengan mengubah keyakinan-keyakinan ir asional yang tertanam dalam diri dan menimbulkan konsekuensi-konsekuensi negatif pada klien.

3. Membantu klien ber komitmen terhadap pilihannya.

Ko nselor menanyakan a pakah klien betul-betul ingin mencapai tujuan ters ebut, dan apakah klien telahbersedia dengan resiko-resiko yang harus dihadapinya. Konselor juga membantu klien mencari insentif y ang dapat digunakan agar klien komit terhadap pili han yangharus dilakukannya.Dalam perkara ini, klien mengatakan bahwa in sent if y ang terp enting dabm dirinyaadakh kepuasanyang dipero lehnya jika dia berhasil. Sedangkan insentif tambahan adakh apabila para penghuni asr ama karyawan dapat menerima dirinya dengan baik.

\section{Tindakan}

Pada tahap ini, konselor melakukan langkah-langkah:

1. Membangun strategi dan perencanaan untuk mencapai tujuan klien.

Ko ns elor menanyakan kepada klien strategi apakah yang pernah dia lakukan untuk mengatasi permasalahannya. Klien mengatakan bahwa dia pernah bert indak tergesa-gesa karena hendak cepat m engatasi masalahnya dan tidak m emikirkan resiko yang akan dih adapinya, selain itu klien juga kurang siap menghadapi rintangan yang ada. Klien men dapat i bahwa strateginya tersebut ti dak efektif.

\section{Contoh:}

Klien pernah bertunangan dengan seorang lelaki bukan karena dia menyukainya tetapi kar ena merasa kasihan terha dap lelaki itu yang memiliki berbagai penyakit serius dan sering membuatnya lemah. Klien sendiri belum yakin mengenai kesiapan dan kesungguhannya untuk bernikah.

Klien pergi bekerja ke luar negeri kedua kalinya dalam rangka untuk menghindar dari kejaran pasangan lesbiannya dan melarikan diri dari kebimbangannya untuk menikah dengan tunangannya. Tetapi itu tidak menyelesaikan masalahnya. 
2. Memilih s tra tegi yang ter baik/s esuai untuk membantu klien kemudian dilanjutkan dengan merancang tindakan.

Konselor memilih untuk menggunakan beberapa teknik dalam Rational Emotive Beh avior (REB). Model AB C merupakan inti dari praktik konseling REB oleh karena itu implementasinya harus mendapatkan perhatian yang lebih mendetail (Dry den \& Neenan, 2004). A mewakili activating event atau peris tiwa pemicu. Terdapat dua jenis $\mathrm{A}$ (activating event) dalam konseling RE B, yang pertama adalah 'A situasional' y ang mengacu pada aspek objektif dari situasi yang mengganggu individu. A kedua adalah 'A kritis' yang mengacu pada aspek klientif dari situasi yang mengganggu individu. Pada umumnya, 'A kritis' merupakan inferensi dari apa yang terjadi pada 'A situasional'.

B mewakili Beliefs atau keyakinan. Key akinan mer upakan kognisi evaluatif a tau pandangan y ang ter struktur terha dap hal-hal di sekitar individu, bis a ber upa pandangan kaku atau fleksibel, ekstrim maup un nonekstrim. Ketika keyakinan individu bersifat rigid maka itu dinamakan 'keyakinan ir rasional' dan biasanya berupa keharusan, kemutlakan, ataupun kewajiban terhadap sesuatu. Individu y ang memiliki keyak in an yang rigid akan cenderung membuat kesimpulan yang ir rasional. C mewakili Consequence, merupakan konsekuensi emosi onal, pikiran dan perilaku yang muncul dari keyaki nan atau belief (B) terhadap situasi pemicu atau activating event (A). Dalam kon seling REB, C yang mengikuti keyaki nan irr asional tentang A yang negatif akan bersifat mengganggu dan disebut kon sekuensi n egatif tidak sehat. Sebaliknya, C yang mengikuti keyakinan rasional tentang A yang negatif mak a sifatnya tidak m engganggu dan disebut kon sekuensi negat if yang sehat (Ellis, 2007; Dryden \& Neenan, 2004).

Kon seling REB merupakan pendekatan konseling y ang dirancang untuk membantu individu meminimalisir gangguan emosi dan perilaku merusak diri, serta mendor ong mereka untuk hidup secara lebihbermakna dan bahagia (Dry den, 2007). Dalam mencapai tujuan ters ebut, konselor REB diharapkan membantu klien untuk: (1) untuk berpikir secara lebih rasional (logis, fleksibel dan ilmiah ); (2) untuk merasa lebih sehat; dan (3) untuk bertindak lebih efisien dalam rangka mencapai tujuan dan sasaran mereka (Dryden \& Neenan, 2004). Teknik REB ini dipilih karena konselor menilai bahwa kebanyakan masalah emosi dan tingkah laku klien bersumber dari perny ataan ti dak rasional yang dibuat oleh kl ien sendiri ketika kehidupan tidak sesuai dengan apa yang dia inginkan. Keyakinan irasional terdiri dari kemutlakan (absolutist), kepercayaan yang dogmat is dan tidak fleksibel, yang biasanya berbentuk "harus, seharusnya, perlu, sebaiknya". Klien juga sering mempunyai kesimpulan menilai diri seperti saya in $i$ manusia yang sangat buruk...' dan 'Saya tidak dapatmelakukan apa-apa'. 
Sebagai pelopor, Ellis menekankan kons ep bahwa"pemikiran yangtidak rasi onal harus ditantang supaya menjadi rasional". Pemikiran yang tidak rasional ini adalah akibat dari proses dan pengar uh bu daya dan pros es pembelajaran. Olehkarena itu, individu harus mengubah fikiran dan kepercayaannya dengan merekonstruksi persepsi dan fikirannya agar menjadi lebih logis dengan menggunakan teknik dan tata cara yang se suai.

3. Konselor membantu klien membuat rancangan yang memungkinkan klien mengikuti strategi dan agenda yang telah ditetapkan.

Konselor menjelaskan kepada klien bahwa rencana ini menuntut kedisiplinan dan konsentrasi klien. Karena klien memilih untuk bekerja dengan teknik-teknik REB, maka dilakukan langkah-langkah sebagai b erikut:

\section{a. Teknik Kognitif}

(1) Konselor membantu klien untuk membedakan antara fikiran-fikiran yang rasional dan tidak rasional.

Klien diberi penjelasan tentang teori ABCDE dari Ellis untuk menjelaskan kepercayaan tidak rasi onalyang menyebabkan masalah klien. Klien juga ditantang untuk mengubah sistem keyakinannya (beliefsystem) dalam menghadapi masalah emosinya. Hal ini dilakukan dengan menciptakan $\mathrm{D}$, "a dispute belief system" yang melawan fikiran tidak rasional yang dimiliki individu.
A: Activating Event/ Situation right now / reality/ physical fact (Peristiwa)

Contoh: Klien mendapatkan banyak teguran dari para penghuni asrama karyawan mengenai tingkahlakunya yangsering merayurayu wani ta lain.

B: Belief system (things they tell themselves)/ Sistem kepercayaan yang dipegang. Klien meyakini bahwa dirinya telah gagal untuk mengubah dirinya menjadi seorang wanita normal. Klien juga percaya bahwa dirinya adalah seor ang yang bur uk karena memiliki tingkah laku yang tidak sama dengan orang lain.

C: Emotional consequences/feelings/Emosi, pemikiran dan tingkah laku yang terganggu akibat dari peristiwa (A) dan sistem keperc ayaan yang dianuti (B). Dalam contoh situasi yang diberikan, klien menunjukkan sim tom gangguan emo si dan fikiran seperti: merasa sedih dan tert ekan sehingga malas melakukan apa pun.

\section{D: Dispute (confirm B or dispute B)}

Kons elor menantang, mendukung dan membetulkan sistem kepercayaan klien dengan mengatakan kesulitan dia untuk menyesuaikan diri tidak berarti dia seor ang yang gagal Dia mendapat t eguran dari or ang lain juga ti dak berarti dia seorang yang buruk. Tidak semua tingkah laku klien yang b erbeda juga langsung dapat diartikan sebagai tingkah laku yang buruk. Oleh karena itu, dia dapat mencoba lagi untuk menjadi normal.

\section{E: Emotion after dispute}

Emosi dan tahap pemikiran individu berubah dari tidak rasional menjadi fikiran yang rasional. Oleh karena itu emosi, pemikiran dan tingkah laku individu menjadi normal lagi. 


\section{Contoh-contoh lain:}

\section{Fikiran tidak rasional}

Konfrontasi

Saya adalah orang yang tidak Apakah anda tidak memiliki sisi baik sama sekali? baik

Semua lelaki a dalah jahat

Apakah anda memiliki bukti bahwa semua lelaki jahat? Berapa orang lelaki yang anda ketahui kejahatannya?

Saya akan merasa tertekan dan Apakah kebahagiaan dan kenyamanan hidup anda sedih kalau K (perempuan yg hanya ditentukan oleh keberadaan K?

disukainya di asrama) pulang

Masa lalu saya yang kelam Mengapa masa lalu yang kelam tersebut hanya menyebabkan saya merasa membuat anda rendah diri di depan lelaki, tetapi rendah diri bila berhadapan tidak didepan wanita? Apakah ini logis? dengan lelaki

Saya benci lelaki yang disukai Lelaki itu tidak membuat kesalahan apapun, dia banyak orang karena dia tidak menyuruh wanita-wanita itu untuk menyebabkan para wanita menyukainya dan bertengkar untuk merebutnya. bertengkar untuk merebutnya

Seorang penulis yang Seorang penulis bisa mendapatkan ide cerita dari mengalami suatu peristiwa mana saja, antaranya buku-buku, film, pengalaman secara langsung akan orang lain, ataupun fantasinya sendiri menghasilkan karya yang lebih baik

(2) Konselor mendorong klien untuk membentuk falsafah hidup baru yang lebih positif. Contohnya:

"Saya memang pernah mengalami masa lalu yang buruk, tapi saya juga berhak mendapatkan masa depan yang lebih baik"

"Perlakuan dan perkataan kawan-kawan di asrama kary awan memang menyakitk an hati saya, tapi hal itu dapat membantu saya mengontrol tingkah laku saya sehingga menjadi lebih baik"

"Saya memang memil iki banyak kelemahan, tetapi itu tidak menjadikan diri saya lebih rendah dari orang lain karena setiap orang memiliki kelebihan dan kekurangannya masing-masing.

(3) Konselor memberikan majalahmajalah yang dapat memberikan pengetahuan mengenai berfikir positif untuk dibaca oleh klien

(4) Konselor menanyakan kesenangan atau hobi klien dan menjelaskan keuntungan memiliki hobi. Dalam hal ini klien mengatakan bahwa dia memiliki hobi menulis dan konselor menyarankan klienuntuk kembali menekuni hobinya tersebut 
b. Teknik Emotif

(1) Konselor memin ta klien untuk berbicara dengan dir inya sendiri dengan berusaha membantah keharus an-keharus an ir asional yang dimilikinya.

(2) Dorong klien untuk memberitahu diri sendiri bahwa

"Saya tida k memerlukan persetujuan orang lain dalam berting kah laku, tetapi tentu saja saya lebih suka apabila mereka suka dengan perilaku saya".

"Saya memang memili ki penga laman buruk dengan beberap a laki-laki, tetapi banyak juga laki-la ki yang baik kepada saya"

(3) Konselor mendor ong klien untuk menggunakan humor dalam menghapus sistem kepercayaan yang irrasional serta untuk menghibur diri

c. Teknik Tingkah Laku

(1) Konselor mendor ong klien untuk secara bertahap mencoba melakukan hal - hal yang takut untuk dilakukannya. Contohnya:

Ko nselor m endorong klien untuk tetap bertemandengan para wanita untuk melatih klien membedakan dorongan untuk bersahabat dengan dorongan untuk bercinta. Pada sesi 3 klien berhasil menjalin persaha batan dengan beberapa penghuniasrama karyawanyang berusia pertengahan baya. Pada sesi 4 klien sudah dapat menjalin persahabatan dengan beberapa penghuni asrama karyawan yang seumur dengannya. Orang-orang inidipilih oleh klien dengan berhati-hati karena takut akan terbawa perasaan lagi.
(2) Konselor mendoro ngklien supaya melakukan sesuatu yang menyenangkan seperti mengikuti program-program pelatihan setiap hari Sabtu dan Minggu. Di situ klien dapat mengikuti berbagai permainan, mendengarkan musik, menyanyi, menari, menonton film dan sebagainya.

(3) Konselor membantu klien membuat rencana mengenai masa depannya. Konselor berdiskusi dengan klien mengenai apa yang ingin dilakukanny a di masa depan. Apakah klien sungguh-sungguh ingin menikahi tunangannya? Pekerjaan apakah yang ingin dia lakukan?

(4) Konselor membantu klien untuk mengembangkan hobinya menjadi salah satu kemahirannya. Kar ena klien mengatakan bahwa dia memiliki hobi menulis, maka ko ns elor mendo ro ngny a untuk mengembangkan lagi hobinya ter sebut. Konselor juga meminta bantuan kepadaseorang wartawan untuk membimbing klien belajar membuat tulis an yang baik.

\section{Penutup}

Set elah mengikuti tujuh sesi konseling Rational Emotive Behavior dengan kerangka 
kerja Skilled Helper Model dari Egan, beberapa kemajuan telah diperoleh klien, terutama berk urangnya fiki ran-fikir an negatif klien. Klien mulai dapatberfikir secara ras ional, lebih terbuka dan mengurangi mekanisme pembelaan dirinya. B erubahnya keyakinan ir asional klien memberik an pengar uh juga pada masalah-masalah yang dikeluhkan klien sebelumnya seperti:

a. Penyesuaian diri klien menjadi lebih baik. Di kalangan ibu-ibu, klien kini lebih dapat diterima karena klien sudah mau menyapa dan berinteraksi dengan penghuni asrama sec ara wajar. Perilaku klien saat ini dinilai berani tapi tetap sopan dan menghargai.

b. Klien dapat menggunakan coping ski lls yang baik untuk mengatasi konfliknya dengan penghuni asr ama (tidak melayani dengan serius, bahkan cenderung menanggapi dengan hu mor)

c. Klien mengatakan b ahwa kecemasannya berkurang karenase karang ini penghuni asrama dapat melihat dengan jelas perubahan tingkah laku klien sehingga gosip t entang klien juga su dah bany ak berkurang

d. Klien mulai dapat membedakan do rongannya untuk berkawan dengan sesama perempuan dan bukannya jatuh cinta kepada s esama perempuan. Oleh kar enany a kli en mulai berani menjalin persahabatan dengan perempuan lainnya. e. Perasaan rendah diri klien juga semakin berkurangkarena tulisanyang dibuatnya dinilai cukup baik dan telah dicetak dalam sebuah majalah.

Dengan dicapainya hasil tersebut, maka dapat dilihat bahwa intervensi yang dilakukan cukup efektif. Hanya dengan 7 s esi kons eling kemajuan yang dicapai kl ien cuk up banyak. Oleh karena itu konseling eklektik layak menjadi alternatif pilihan interv ensi dalam menangani klien.

\section{Daftar Pustaka}

APA Dictionary Online. https:// diction ary.apa.org/eclectic-cou nseling

Corey, G. (2015). Theory and practice of counseling and psy chotherapy. Toronto: Nelso n Education.

Dryden, W., Neenan, M. (2004). Ratinal Emotive Behavioural Counselling in Action ( $3^{\text {rd }}$ edition). London: Sage Publication Ltd.

Dryden, W. (2007). Dry den's Handbook of Individual Therapy $\left(5^{\text {th }}\right.$ edition). Singapore: Sage Publications Asia Pasific Pte Ltd.

Egan, G. (2014). The Skilled Helper: A problem management and opportunity-development approach to helping (10 $0^{\text {th }}$ edition). California: Thomson Brooks/Cole

Ellis, A. (2 007). Terapi R.E.B agar Hidup Bebas Derita (Terjemahan).Yogyakarta: B-First.

Faris, A., van $\mathrm{O}$ oi jen, E. (2012). I ntegr ative Counselling and Psychotherapy: A Relational Approach. Singapor e: Sage Publication Asia Pasific Pte Ltd.

Jenkins, P. (2000).'Gerard Egan's Sk illed Helper model' in S. Palmer and R. Woolfe (eds). Intergrative and Eclectic Counselling and Psychotherapy. London: Sage. 
Kaslow, F.W., Lebow, J.L. (2002). Comprehensive Handbook of Psyc hoth erapy, Integrative/Eclectic. New York: John Wiley \& Sons

Lambert, M.J., (2013). The efficacy and effectiveness of psy ch otherapy. M.J. Lambert (Ed). Bergin and Garfield's Handbook of Psychotherapy and Behavior Change $\left(6^{\text {th }}\right.$ ed). New York: John Wiley \& Sons.

Winkel, W.S., Hastuti, M.M., (2010). Bimbingan dan Konseling di Institusi Pendidikan. Jakarta: PT. Grasindo
Woolfe, R., Strawbridge, S., Douglas, B., Dryden, W., 2009. Handbook of Counselling Psychology (3th eds). Singapore: Sage Publication Asia Pasific Pte Ltd.

Wo sk et, V. (2016). The Therapeutic Use of Self: Couns elling practice, researc $h$ and supervision. Lon don: Routledge. https://doi.org/10.4324/ 9780203772263

Wosket, V. (2007). Egan's Skilled Helper Mo del: Develop ments and Ap plications in Counselling. London: Taylor \& Francis 